NBER WORKING PAPER SERIES

CHALLENGES TO MISMEASUREMENT EXPLANATIONS FOR THE U.S. PRODUCTIVITY SLOWDOWN

Chad Syverson

Working Paper 21974

http://www.nber.org/papers/w21974

\author{
NATIONAL BUREAU OF ECONOMIC RESEARCH \\ 1050 Massachusetts Avenue \\ Cambridge, MA 02138 \\ February 2016
}

I thank Erik Brynjolfsson, Dave Byrne, Austan Goolsbee, Bob Gordon, Jan Hatzius, Pete Klenow, and Hal Varian for comments. I have no financial interests relevant to this study. The views expressed herein are those of the author and do not necessarily reflect the views of the National Bureau of Economic Research.

NBER working papers are circulated for discussion and comment purposes. They have not been peerreviewed or been subject to the review by the NBER Board of Directors that accompanies official NBER publications.

(C) 2016 by Chad Syverson. All rights reserved. Short sections of text, not to exceed two paragraphs, may be quoted without explicit permission provided that full credit, including (C) notice, is given to the source. 
Challenges to Mismeasurement Explanations for the U.S. Productivity Slowdown

Chad Syverson

NBER Working Paper No. 21974

February 2016

JEL No. E2,O3,O4

\begin{abstract}
$\underline{\text { ABSTRACT }}$
The U.S. has been experiencing a slowdown in measured labor productivity growth since 2004. A number of commentators and researchers have suggested that this slowdown is at least in part illusory, because real output data have failed to capture the new and better products of the past decade. I conduct four disparate analyses, each of which offers empirical challenges to this "mismeasurement hypothesis." First, the productivity slowdown has occurred in dozens of countries, and its size is unrelated to measures of the countries' consumption or production intensities of information and communication technologies (ICTs, the type of goods most often cited as sources of mismeasurement). Second, estimates from the existing research literature of the surplus created by internet-linked digital technologies fall far short of the \$2.7 trillion or more of "missing output" resulting from the productivity growth slowdown. The largest - by some distance - is less than one-third of the purportedly mismeasured GDP. Third, if measurement problems were to account for even a modest share of this missing output, the properly measured output and productivity growth rates of industries that produce and service ICTs would have to have been multiples of their measured growth in the data. Fourth, while measured gross domestic income has been on average higher than measured gross domestic product since 2004_perhaps indicating workers are being paid to make products that are given away for free or at highly discounted prices - this trend actually began before the productivity slowdown and moreover reflects unusually high capital income rather than labor income (i.e., profits are unusually high). In combination, these complementary facets of evidence suggest that the reasonable prima facie case for the mismeasurement hypothesis faces real hurdles when confronted with the data.
\end{abstract}

\author{
Chad Syverson \\ University of Chicago \\ Booth School of Business \\ 5807 S. Woodlawn Ave. \\ Chicago, IL 60637 \\ and NBER \\ chad.syverson@chicagobooth.edu
}


The United States is experiencing a slowdown in measured labor productivity growth. From 2005 through 2015(Q3), labor productivity growth has averaged 1.3\% per year. This is down from a trajectory of 2.8\% average annual growth sustained over 1995-2004. ${ }^{1}$

This slowdown is statistically and economically significant. A $t$-test comparing average quarterly labor productivity growth rates over 1995-2004 to those for 2005-2015(Q3) rejects equality with a p-value of 0.011 , and if the annualized 1.5\% drop in labor productivity growth were to be sustained for 25 years, it would compound to a $45 \%$ difference in income per capita. Unless the slowdown is an artifact of measurement, it is serious-especially if it persists past its initial decade.

The slowdown does not appear to be due to cyclical phenomena, whether economic or measurement related. Fernald (2014) shows that the slowdown started before the onset of the Great Recession and is not tied to "bubble economy” phenomena in housing or finance. This work, along with the analysis in Byrne, Oliner, and Sichel (2013), ties the slowdown to a reversal of the productivity accelerations in the manufacturing and utilization of information and communication technologies (ICTs) that drove the 1995-2004 pace. One should therefore not expect measured labor productivity in the U.S. to naturally emerge from the slowdown solely as a consequence of emerging from the Great Recession.

The debate about the cause of the slowdown is ongoing. Gordon (2015) points to multiple possible explanations and ties the current slowdown to the one in 1974-1994, viewing the 19952004 acceleration as a one-off aberration. Cowen (2011) shares these views and enumerates multiple reasons why innovation —at least the kind that leads to changes in measured productivity and income-may slow. Tarullo (2014) suggests that the slowdown in U.S. business dynamism documented by Decker, Haltiwanger, Jarmin and Miranda (2014) and Davis and Haltiwanger (2014) may have a role. Some have argued that there are reasons to be optimistic that the slowdown may reverse itself. Baily, Manyika, and Gupta (2013) point to potential innovation opportunities in multiple sectors. Syverson (2013) notes that the productivity growth from electrification and the internal combustion engine-a prior diffusion of a general purpose technology_came in multiple waves, implying that the 1995-2004 acceleration need not be a one-time event.

\footnotetext{
${ }^{1}$ This fast/slow cycle followed on the heels of another much-studied-but-still-debated slowdown. After labor productivity growth averaged 2.7\% per year from 1947-1973, it fell to 1.5\% per year over 1974-1994.
} 
This latter set of work is more optimistic than the former about future productivity growth, but it accepts the slowdown as reflecting a true drop in the rate of economic growth. A separate explanation for the slowdown forwarded by several parties in varied forms (e.g., Brynjolfsson and McAfee, 2011 and 2014; Mokyr 2014; Alloway, 2015; Byrne, Oliner, and Sichel 2015; Feldstein 2015; Hatzius and Dawsey 2015; Smith 2015) is that it is substantially illusory. The theme of these arguments is that true productivity growth since 2004 has not slowed as much as measured (or perhaps even accelerated), but recent productivity gains are not being reflected in the productivity statistics. That is, due to measurement problems, the new and better products of the past decade are for some reason not being captured in productivity metrics.

This mismeasurement could take one of two related forms in the data. One would occur if a smaller share of the utility that these products provide is embodied in their prices than was the case for products made before 2004. If this were true, measured output growth would slow even as total surplus growth continued apace. The second form of mismeasurement would occur if the products' price deflators were rising too fast (or falling too slowly) relative to their pre-2004 changes. This would understate quantity growth as backed out from nominal sales. ${ }^{2}$

The prima facie case for this assertion, which for brevity I refer to as the mismeasurement hypothesis, is plausible. Many of the fastest-diffusing technologies since 2004, like smartphones, online social networks, and downloadable media, involve consumption of products that are timeintensive but do not impose a large direct monetary cost on consumers. If one considers the total expenditure on such products to be both the monetary price and the value of time spent consuming them, a revealed preference argument would suggest they deliver substantial utility (Becker, 1965). At the same time, the fact that they are not particularly expensive (at least relative to consumers' supposed interest in them) could result in a relatively modest portion of their delivered consumption benefit to be reflected in GDP.

In this study I explore the quantitative plausibility of the mismeasurement hypothesis. One fact dominates the discussion: had the measured productivity slowdown not happened, measured GDP in 2015(Q3) would be, conservatively, \$2.7 trillion (15.0\%) higher than it is.

\footnotetext{
${ }^{2}$ These issues have arisen before. Diewert and Fox (1999) discuss related productivity measurement problems in the context of an earlier slowdown, arguing that there were several plausible sources of mismeasurement. The pricedeflator-based interpretation of the measurement problem evokes the Boskin Commission report (U.S. Congress 1996), which argued that the CPI methodology at the time overstated inflation and therefore understated growth. Many of the commission's suggested changes, including those specifically aimed at better measurement of new products and technologies, were implemented before 2004. See Klenow (2003).
} 
This is $\$ 8400$ for every person or $\$ 21,900$ for every household in the U.S. For the mismeasurement hypothesis to fully explain the productivity slowdown, the losses in measured incremental gains for new technologies would need to be at or around this level. To explain even a substantial fraction of the slowdown, current GDP measures must be missing hundreds of billions of dollars of incremental output (with no accompanying employment growth, moreover).

As I detail here, several patterns in the data, each looking at the mismeasurement hypothesis from different directions, pose challenges for the hypothesis.

The first pattern is that the productivity slowdown is not unique to the U.S. It has occurred with similar timing across at least two dozen other advanced economies. While measurement problems could possibly be correlated across these countries, more problematic for the hypothesis is that fact that the magnitude of the slowdown in a country (of which there is nontrivial variation) is unrelated to the relative size of information and communication technologies (ICTs) in the country's economy. This result obtains whether this "ICT intensity" is measured in consumption or production terms. It echoes other work (Cardarelli and Lusinyan 2015) showing variations in the slowdown across U.S. states are not related to state-level ICT intensity.

The second pattern comes from the research literature that has attempted to measure the consumer surplus of the internet. These efforts are based on the notion that many of the newer technologies that could create large surplus with little revenue require internet access, which makes purchase and use of such access a metric for the gains from such technologies. This offers a way to quantify the role mismeasurement might have in the measured productivity slowdown. The results from this literature suggests this role is limited; most of the estimates of the value of internet-linked technologies are at least an order of magnitude smaller than the trillions of dollars of measured output lost to the slowdown. Even the largest, which explicitly accounts for the time people spend online and is computed with very generous assumptions about the value of that time, totals to about one-third of the missing output.

The third pattern is observed in the incremental output of industries that make and service ICT/digital technologies. If the mismeasurement hypothesis were to account entirely (or almost so) for the productivity slowdown, the implied change in real revenues of these industries would be five times their measured revenue change. Incremental real value added would have been six times the observed change, and true labor productivity in the industries would have risen 363\% 
over 11 years. Even if measurement problems were to account for only one-third of the post2004 missing GDP (recall that one-third is the largest estimate by some distance from the literature mentioned above), this would imply a true growth rate of these industries that is multiples of what was observed in the data.

The fourth pattern arises in the comparison of data on gross domestic income (GDI) and gross domestic product (GDP). Conceptually, these two are equal by an accounting identity. However, they are never equivalent in measure because they are computed with different source data. Since 2004, GDI has outstripped GDP by an average of $0.4 \%$ of GDP per year. This pattern is consistent with workers being paid to produce goods that are being given away for free or are being sold at steep discounts, consistent with the mechanism behind the mismeasurement hypothesis. However, I show that GDI began to be larger than GDP in 1998-several years before the productivity slowdown and, indeed, in the midst of a well-documented productivity acceleration. Additionally, a breakdown of GDI by income type shows that GDI growth over the period has been driven by historically high capital income (e.g., corporate profits). Labor income has actually fallen. This is opposite the implication of a "workers paid to make products sold free” story.

I detail all of these patterns below, after starting with a computation of the missing output lost to the productivity slowdown. I view none of these four patterns in isolation as being dispositive about the plausibility of the mismeasurement hypothesis. Together, however, they pose challenges to the mismeasurement hypothesis's ability to explain a substantial part of the productivity slowdown.

\section{Calculating the Missing Output}

I first compute the implied lost output due to the productivity slowdown. Using quarterly labor productivity data from the U.S. Bureau of Labor Statistics for the entire nonfarm business sector, I calculate average quarterly productivity growth over four post-WW2 periods (period averages are inclusive of endpoint years): 1947-1973, 1974-1994, 1995-2004, and 20042015(Q3). Past research has shown that average productivity growth has inflection points at or around the transitions between the period, and work on both the most recent and prior productivity slowdowns (e.g., Byrne, Oliner, and Sichel 2013) has used these periods. Table 1 shows average productivity growth rates along with their annualized values for each period. As 
is clear in the table, after 2004 measured labor productivity growth fell by more than half from its 1995-2004 average.

Labor productivity is defined as the ratio of real output to labor inputs, so it is straightforward to compute what counterfactual output would have been at any moment after 2004 had productivity growth not slowed. The drop in average quarterly labor productivity growth between 1995-2004 and 2005-2015(Q3) is 0.381\% (=0.711 - 0.330), so counterfactual output in any post-2004 period $t$ is $Y_{c}=Y_{a}(1.00381)^{q}$, where $Y_{c}$ is counterfactual output, $Y_{a}$ is actual observed output, and $q$ is the number of quarters between 2004(Q4) and $t$. Counterfactual output in $2015(\mathrm{Q} 3)$ is thus $17.8 \%$ higher $\left(1.00386^{43}=1.178\right)$ than observed output in that period. Note that this exercise does not change labor inputs. Counterfactual output still reflects the observed movements in labor inputs over the period, like the considerable decline during the Great Recession. This exercise therefore does not assume the employment downturn of the slowdown period away. ${ }^{3}$

Annualized nominal GDP in 2015(Q3) was \$18.060 trillion. If I were to apply the counterfactual extra productivity growth of $17.8 \%$ to this value, this would imply the amount of output "lost" due to the productivity slowdown is $\$ 3.21$ trillion per year- $\$ 10,000$ per capita and $\$ 26,000$ per household. ${ }^{4}$

It is not immediately obvious if GDP is the correct base to apply the counterfactual growth to. The BLS labor productivity series I use applies to all nonfarm business activity. This leaves out farming-, government-, and household-related output, which jointly account for about one-quarter of GDP. ${ }^{5}$ If productivity growth systematically differed in these excluded sectors,

\footnotetext{
${ }^{3}$ An implication of the mismeasurement hypothesis is that the reported output deflator does not reflect true price changes and should have grown more slowly than what was measured. It is therefore instructive to compare the average growth rates of the implicit price deflator for the BLS productivity series in the 1995-2004 and 20052015(Q3) periods. Price deflator growth as measured was in fact higher in the latter period, though only slightly. The deflator grew an average of $0.36 \%$ per quarter from $1995-2004$ and $0.42 \%$ per quarter from $2005-2015(Q 3)$. Compounded out over the 43 quarters of the latter period, the deflator grew a cumulative $2.4 \%$ more than had it remained at its earlier trajectory. To the extent that this acceleration might reflect real output mismeasurement (and to be clear, the fact that it did accelerate does not imply that it shouldn't have), it would only explain about oneeighth of the measured slowdown.

${ }^{4}$ I use the U.S. Census 2015 estimates of a population of 321 million living in 123 million households.

${ }^{5}$ The BLS excludes government, nonprofits, and paid employees of private households from its labor productivity series because the outputs of these sectors in GDP “....are based largely on the incomes of input factors. In other words, the measure is constructed by making an implicit assumption of negligible productivity change.” (http://www.bls.gov/lpc/faqs.htm) The value of owner-occupied dwellings is left out "because this sector lacks a measure of the hours homeowners spend maintaining their home.”
} 
the "lost" output could be smaller than 3.21 trillion per year (if labor productivity growth in the excluded activities didn't slow as much as in nonfarm business) or larger (if productivity in the excluded activities slowed more). As long as productivity growth did not actually accelerate in these excluded sectors - which seems a fair assumption-a very conservative estimate of lost output would apply the $17.8 \%$ slowdown only to the three-fourths of GDP that the labor productivity series covers directly. This lower bound implies at least $\$ 2.40$ trillion of lost output.

Some additional data can refine this lower bound estimate. First, the BLS does compute a productivity series that adds the farming sector (which accounts for about $1 \%$ of GDP) to the set of covered industries. This series experienced an even larger productivity slowdown than the nonfarm business series, falling from an average growth per quarter of 0.741\% over 1995-2004 to $0.328 \%$ for $2005-2015(Q 3)$. This implies an even larger amount of “missing” output— $\$ 3.5$ trillion applied to GDP or a lower bound of about \$2.6 trillion when applied only to the directly covered sectors. Second, I combined an unpublished BLS series of total economy aggregate hours through 2014(Q3) with the real GDP index from the BEA to compute a total economy labor productivity measure. ${ }^{6}$ This metric indicates a drop in productivity growth between 19952004 and 2005-2014(Q3) of 0.312\% per quarter. Had this series seen the same productivity change as in the nonfarm private business series in 2014(Q4)-2015(Q3), the slowdown would be 0.324\% per quarter. Applying this to all of GDP (which, here, the productivity metric spans) implies lost output due to the productivity slowdown of $\$ 2.70$ trillion per year- $\$ 8400$ per capita or $\$ 21,900$ per household.

Thus the amount of output lost to the productivity slowdown ranges somewhere between \$2.4 trillion and \$3.5 trillion per year. Going forward, I will analyze the case for the mismeasurement hypothesis using the $\$ 2.7$ trillion value implied by the "whole economy" productivity metric just discussed. This is conservative in the sense that it leaves less total lost output for the hypothesis to explain than would applying the BLS measured productivity slowdown to all of GDP.

Whether the mismeasurement hypothesis is presumed to act through output gains disproportionately flowing into consumer surplus rather than GDP or through incorrect price deflators, the implication is the same: U.S. consumers benefited from this missing output; it just was not reflected in measured GDP. Any evaluation of the hypothesis needs to put estimates of

\footnotetext{
${ }^{6}$ I thank Bob Gordon for sharing this hours data.
} 
mismeasurement on productivity in the context of measures of this missing output. To explain the entire slowdown as a figment of measurement problems implies that every person in the country in 2015 enjoyed an average additional surplus of \$8400 that did not exist in 2004.

It is important to recognize that the question is not whether the average consumer surplus in 2015 is \$8400 per capita. By definition GDP does not measure, nor ever has measured, consumer surplus. Nominal GDP values output at its market price; consumer surplus is the extent to which willingness to pay is above the market price. And there surely was consumer surplus, probably substantial, in 2004 just as in 2015. The question instead is whether it is plausible that technological growth between 2004 and 2015-and in particular the advent and diffusion of digitally oriented technologies like smartphones, downloadable media, and social networks that have been the most cited examples_created $\$ 8400$ per person in incremental and unmeasured value above and beyond any consumer surplus that already existed in goods and services present in 2004 and was brought forward to 2015.

\section{The Extent of the Productivity Slowdown Is Not Related to Digital Technology Intensity}

Before addressing the quantitative plausibility of the mismeasurement hypothesis in U.S. data, I first zoom out to look at patterns across countries. Several studies have noted recent productivity slowdowns in other economically advanced countries (e.g., Mas and Stehrer, 2012; Connolly and Gustafsson, 2013; Pessoa and Van Reenen, 2014; Goodridge, Haskel, and Wallis, 2015). Furthermore, Cette, Fernald, and Mojon (2015) document that, as in the U.S., these slowdowns began before the 2008-09 financial crisis and recession.

Given the relatively technology-heavy profile of U.S. production (and citation of digital technologies produced by U.S.-based multinationals as prime examples of the sources of mismeasurement), one might argue that the fact that a productivity slowdown has occurred across a number of economies makes a measurement-based explanation for the slowdown less likely. Still, it could be that similar measurement problems have arisen in multiple countries. To more directly test whether technology-linked mismeasurement is behind the multiple slowdowns, I test if there is any systematic relationship between the extent of a slowdown in a country and the importance of ICTs, whether on the production or consumption side, to that country's economy. 
I conduct this test using OECD labor productivity growth data, which contains yearly percentage changes in real GDP per worker-hour. Growth rates are reported for 38 countries in 2014 — the latest year for which data are available — but only 30 have data going back to 1995 as needed to directly compare to the US slowdown. (Another five countries have data beginning in 1996.) I combine this productivity growth data with two measures, also from the OECD, of the ICT intensity of an economy. The consumption-side measure is the fraction of a country's households with broadband internet access. My data are taken from 2007, the year in which this data was most widely available: 28 countries, 25 of which overlap with those for which I can compute the change in productivity growth between 1995-2004 and 2005-2014. Obviously broadband access has increased since this time, but here I am interested in the much more stable cross-sectional variation. The production-side intensity metric is the share of the country's value added accounted for by ICT-related industries. This data is only available for 2011. It spans 28 countries, 24 of which overlap with my productivity slowdown sample. ${ }^{7}$

The ubiquity of the productivity slowdown is readily apparent in the data. Labor productivity growth decelerated between 1995-2004 and 2005-2014 in 29 of the 30 countries in the sample (Spain is the only exception). Labor productivity growth across the sample's countries fell on average by 1.2\% per year between the periods, from 2.58\% during 1995-2004 to 1.38\% over 2005-2014. There was substantial variation in the magnitude of the slowdown, with a standard variation of $0.9 \%$ per year across countries. While the crisis years of 2008-09 saw unusually weak productivity growth - these were the only two years with negative average productivity growth across the sample - the slowdown does not merely reflect the crisis years. Calculating later-period average productivity growth excluding 2008-09 still reveals slowdowns in measured productivity growth in 25 of 30 countries, with an average drop of $0.72 \%$ per year (from $2.58 \%$ to $1.86 \%$ ). Similarly, computing the prior period average productivity growth using only 1996-2004 data in order to allow for an expanded sample returns the same results: productivity growth slows between the periods in 33 of 35 countries (the exceptions being Spain and Russia).

As for the covariance between the size of a country's slowdown and its ICT intensity, Figure 1a plots each country's change in average annual labor productivity growth between

\footnotetext{
${ }^{7}$ This being OECD data, the countries in the dataset are OECD members and as such are a selected sample of the world's countries. That doesn't pose any particular problem here, as the point is that the slowdown is present in multiple locations, not necessarily that it is everywhere.
} 
1995-2004 and 2005-2014 against the fraction of the country's households that have broadband access. There is no obvious relationship to the eye, and this is confirmed statistically. Regressing the change in labor productivity growth on broadband penetration yields a coefficient on broadband of -0.001 (s.e. $=0.008$ ). The point estimate implies that a one standard deviation difference in broadband penetration is associated with a one-fiftieth of a standard deviation difference in the magnitude of the slowdown. There is simply no relationship between a country's ICT consumption intensity—at least as reflected in broadband access—and the size of its productivity slowdown.

On the production side, Figure 1b plots the change in average annual labor productivity versus ICT-producing industries' share of the country's value added. Here the visual is less obvious, but as with consumption-based ICT intensity, a regression yields a statistically insignificant relationship. The coefficient on ICT intensity is -0.110 (s.e. $=0.095$ ). To the extent any relationship exists, it would be due completely to the outlier Ireland, which has an ICT value added share of $11.9 \%$, double the sample average. Removing Ireland from the sample yields a coefficient on ICT intensity of -0.029 (s.e. $=0.123$ ); this point estimate correlates a one standard deviation difference in ICT share to a one-twentieth of a standard deviation change in the slowdown's magnitude.

Similar results obtain both qualitatively and quantitatively if I instead measure the productivity slowdown using later-period growth rates that exclude 2008-09 or the larger sample with 1996-2004 as the early period. This is not surprising given that the correlations between the three productivity slowdown measures are all above 0.9 .

Thus the productivity slowdown is not unique to the U.S., but rather has occurred in at least two dozen advanced economies. More directly leaning against the mismeasurement hypothesis is the fact that the size of the slowdown in a country is not systematically related to measures of the intensity of ICT-related technologies consumption or production in that country. These results echo and complement the findings in Cardarelli and Lusinyan (2015), who show differences in the slowdown in total factor productivity growth across U.S. states are uncorrelated with measures of states' ICT intensities, both as inputs and outputs in production.

\section{Estimates of Internet-Linked Technologies' Surplus from the Research Literature}


To examine the quantitative plausibility of the measurement hypothesis in more detail, I review the several attempts researchers have made to measure the consumer surplus of newer technologies like those discussed in the context of the hypothesis. While not always explicitly motivated by the post-2004 measured productivity slowdown (some predated its recognition among scholars), these analyses were impelled by a similar notion: certain newer technologies, those tied to internet access in particular, may have an exceptionally high ratio of consumer surplus to observed expenditure. Estimates of these values, which I update using the most recent data available, offer insight into the potential ability of such technologies to explain the productivity slowdown.

Greenstein and McDevitt (2009) estimate the consumer surplus created by broadband access. They choose broadband because, as an access channel, its price at least partially embodies the surplus created by otherwise unpriced technologies (e.g., internet search, some downloadable media, social networking sites, etc.). ${ }^{8}$ They estimate that the new consumer surplus created by households that switched from the earlier technology (dialup) was between $31-47 \%$ of broadband's incremental revenue over dialup. At the end of their analysis sample in 2006, this consumer surplus totaled \$4.8-6.7 billion. In 2015, total U.S. broadband revenues are estimated to be $\$ 55$ billion. ${ }^{9}$ Supposing broadband's overall ratio of consumer surplus to revenues is the same in 2015 as Greenstein and McDevitt (2009) estimated, this implies that the consumer surplus of broadband was between $\$ 17-26$ billion in 2015. Some of this value is likely priced into GDP indirectly through broadband's use by producers as an intermediate input, and as such should not be considered part of the missing output due to the productivity slowdown, but in any case even absent any such adjustment this surplus is two orders of magnitude smaller than the more than $\$ 2.7$ trillion of missing output.

Dutz, Orszag, and Willig (2009) apply demand estimation techniques to household data on internet service take-up and prices. They estimate a consumer surplus from broadband (again relative to dialup) on the order of $\$ 32$ billion per year in 2008. To scale up this value for the growth in broadband since then, I use the fact that their estimates implied the same consumer surplus was $\$ 20$ billion in 2005. Assuming this robust $60 \%$ growth over 3 years (17\% CAGR)

\footnotetext{
${ }^{8}$ As Greenstein (2013) notes, "Looking at broadband demand, which does have a price, helped capture the demand for all the gains a user would get from using a faster form of Internet access."

${ }^{9}$ http://www.statista.com/statistics/280435/fixed-broadband-access-revenues-in-the-united-states/
} 
held until 2015, consumer surplus in 2015 would be $\$ 96$ billion. While this is notably larger than the Greenstein-McDevitt valuation, it is still only 3.6\% of $\$ 2.7$ trillion.

Rosston, Savage, and Waldman (2010) use a different methodology and dataset in another attempt to measure the broadband's consumer surplus. Their estimate is $\$ 33.2$ billion in 2010. I bring this forward to 2015 using their assessment that this surplus had doubled or perhaps even tripled between 2003 and 2010, which implies a CAGR between 10.4\% and 17.0\% (which as it happens is on the order of the Dutz et al. (2009) growth rate). This extrapolation implies consumer surplus ranged between $\$ 54-73$ billion in 2015. Once again, this is miniscule compared to the lost output.

Nevo, Turner, and Williams (2015) use household-level data on broadband purchases to estimate a dynamic model of broadband demand. They find an average consumer surplus among households in their data between $\$ 85-112$ per month (\$1020-1344 per year) in 2012. Applying this to the $80 \%$ of households in the U.S. that had broadband access in 2015, this still totals to at most $\$ 132$ billion—-larger than the estimates above, but again less than 5\% of the $\$ 2.7$ trillion in missing GDP. ${ }^{10}$

Goolsbee and Klenow (2006) do something different. They use the time people spend online as an indicator of "full expenditure" on internet-based technologies. In their methodology, consumption of a good generally involves expenditure of both income and time. Therefore even if financial expenditures on a good are relatively small, the good can deliver substantial welfare if people spend a lot of time consuming it. They argue this is a realistic possibility for the internet, which in their data (for 2005) has a time expenditure share 30 times greater than its income expenditure share.

Applying their theoretical framework to data, they find that the consumer surplus of internet access could be as large as 3\% of full income (the sum of actual income and the value of leisure time). This surplus would be $\$ 3000$ annually for the median person in their dataset. Brynjolfsson and Oh (2012) extended this analysis with updated data. They pay particular

\footnotetext{
${ }^{10}$ They also use their estimates to infer the total surplus (revenues plus consumer surplus) of access to $1 \mathrm{~Gb} / \mathrm{s}$ networks, which is currently unavailable in most locations. This extrapolation implies a total surplus of \$3350 per year. Some of this would surely be captured as revenues of downstream firms and thus measured in GDP. A conservative price for this service would be $\$ 900$ per year, so consumer surplus per household would be around $\$ 2450$. Even if product were obtained by every household in the country that has broadband, this adds up to $\$ 241$ billion of consumer surplus, $9 \%$ of $\$ 2.7$ trillion.
} 
attention to incremental gains from free internet services, valuing these at over $\$ 100$ billion (about \$320 per capita) annually.

To extend the Goolsbee-Klenow value-of-time analysis to the question of the mismeasurement hypothesis, I must first compute total income in 2015. Disposable personal income totaled \$13.51 trillion, about \$42,100 per capita, in 2015(Q3). For the value of leisure time, I start with the fact that according to the American Time Use Survey, the average person in 2014 spent 10.8 hours a day on non-work-related, non-personal-care (mostly sleep) activities. I make the generous assumptions that all of these 10.8 hours are leisure time and that people value them at the average after-tax wage of \$21.90, regardless of employment status and whether the hours are inframarginal or marginal. ${ }^{11}$ This yields a total annual value of leisure time of about $\$ 86,300$ per person. Adding this to personal income gives a total income equal to $\$ 128,400$ per capita. Applying the Goolsbee-Klenow top-end estimate of 3\%, I end up with a measure of the consumer surplus from the internet in 2015 of around \$3850 per capita. Assuming this surplus accrues mainly to the $80 \%$ of people with broadband access in their household, the aggregate benefit is $\$ 990$ billion. Going through the same set of computations with 2004 data (when broadband penetration was about $12 \%$ according to OECD data) and subtracting the result so as to estimate incremental gains from broadband-based technologies yields a post-2004 incremental surplus from broadband of $\$ 842$ billion. $^{12}$

The Goolsbee-Klenow time-based estimate is by far the highest valuation of the internet in the literature, essentially an order of magnitude larger than the other estimates. I constructed it using very expansive assumptions about the value of leisure time. And yet it is still less than onethird the $\$ 2.7$ trillion of lost income from the productivity slowdown.

Most of the technologies cited by proponents of the mismeasurement hypothesis require internet access of some sort, so these estimates of the surplus delivered by that gateway should

\footnotetext{
${ }^{11}$ According to the Bureau of Labor Statistics employment data, average pre-tax hourly earnings for all nonfarm private business employees were $\$ 25.08$ over the third quarter of 2015. To impute an after-tax wage, I multiply this value by the ratio of that quarter's disposable personal income (\$13.51 trillion) to total pre-tax personal income (\$15.47 trillion), an average tax rate of $12.7 \%$.

12 The specific figures for 2004 are $\$ 9.00$ trillion of nominal disposable income $(\$ 30,700$ per capita given a population of 293 million), 11.0 hours of leisure time per day, and \$18.19 per hour after-tax nominal hourly earnings (based on BLS earnings data for 2006, the start of the all-worker-compensation series). This implies a total nominal income of \$103,800 per capita. Applying the 2004-2015(Q2) GDP deflator ratio of 1.230 and multiplying by the Goolsbee-Klenow estimate of 3\% yields a benefit of \$3850 per capita in 2015 dollars. This is the same as the 2015 figure, so all incremental surplus from broadband by this calculation comes from diffusion of broadband to a larger population. This increase in population with broadband is $0.8 * 321$ million $-0.12 * 293$ million $=222$ million.
} 
embody the surplus of the technologies that are not priced on the margin. Nevertheless, it is possible that some post-2004 technologies that deliver a high ratio of consumer surplus to revenue do not require internet access and as such would not be valued in the aforementioned estimates. The numbers above indicate, however, that to quantitatively explain the bulk of the productivity slowdown, these products would need to deliver surplus that is both somehow not priced either directly or through complementary goods and services, and that is as large as or larger than the biggest estimates of the surplus of internet-linked products.

\section{Estimating Consumer Surplus of New Technologies from Their Output}

I conduct a separate calculation of the quantitative plausibility of the mismeasurement hypothesis by relating the $\$ 2.7$ trillion of missing GDP to the value added-and for reasons explained below, revenues — of products associated with post-2004 technologies. I take an expansive view of which products include such technologies in an attempt to construct something of an upper bound of the lost output that can be explained by the hypothesis.

The first step in the calculation is to select the set of technologies that, if GDP mismeasurement results from the migration of value from output to consumer surplus since 2004, are the most likely to have seen such a change. I include the following sectors in this group: computer and electronic products manufacturing (NAICS 334), the entire information sector (NAICS 51), and computer systems design and related services (NAICS 5415). The first and last are self-explanatory. The information sector includes the following four subindustries: publishing (including software), except internet; motion picture and sound recording; broadcasting and telecommunications; and data processing, internet publishing, and other information services. To the point above about the internet as an access portal, both internet service providers and mobile telephony carriers are in this sector (in particular, NAICS 517, telecommunications).

These industries comprise the segments of the economy most likely to produce the technologies that are the focus of claims of the mismeasurement hypothesis. They also doubtlessly contain activity that has not seen considerable technological expansion over the past decade (or even the past couple of decades, for that matter). As will be clear, this over-expansive definition of the output tied to the mismeasurement hypothesis is conservative in the sense that it will tend to overestimate the missing output these industries might account for. 
The combined value added of these industries in 2014 — the latest year for which the necessary industry breakdowns are currently available-were as follows: computer/electronics manufacturing, $\$ 268.0$ billion; information, $\$ 824.7$ billion; computer systems design and services, \$249.5 billion. This totals to \$1.34 trillion. To approximate 2015 value added, I assume that the industries’ average annual nominal value added growth for 2014-2015 held at 4.3\%, the average over 2011-2014. This implies a total value added of \$1.40 trillion in 2015.

At the precipice of the productivity slowdown in 2004, nominal value added of the sectors was $\$ 945.3$ billion ( $\$ 201.5$ billion in computer/electronics manufacturing, $\$ 620.8$ billion in information, and $\$ 123.0$ billion in computer systems design and services). Applying the BEA value added price indices of the three sectors yields 2004 value added expressed in 2014 dollars: \$820.9 billion. ${ }^{13}$ Extrapolating by assuming another year of 2011-2014 average annual real value added growth of 4.1\% yields an equivalent 2004 value added of $\$ 854.5$ billion in 2015 dollars.

These industries therefore saw measured real value added growth between 2004 and 2015 of about $\$ 545$ billion (= $\$ 1.40$ trillion $-\$ 854.5$ billion). If measurement problems in the industries’ products are to account for the lion’s share of \$2.7 trillion in missing GDP, the incremental consumer surplus these industries would have created would need to be five times their measured incremental value added. Another way to express this is, if the incremental consumer surplus implied by the mismeasurement hypothesis would have in fact been captured as measured value added (and therefore the productivity slowdown observed in the data never materialized), the real value added of the industries would have increased by $440 \%$ (( $\$ 1.40$ trillion $+\$ 2.70$ trillion) $/ \$ 854.5$ billion), six times the $64 \%$ growth ( $\$ 1.40$ trillion $/ \$ 854.5$ billion) that was actually observed in the data. This is an enormous amount of mismeasurement. Even to account for just one-third of the missing output, which was by far the largest estimate of surplus from internet-related products discussed in the prior section, the industries' “correct” value

\footnotetext{
${ }^{13}$ This method divides the industries' summed nominal value added in 2004 by a Tornqvist price index I constructed for the combined industries. This index is equal to the average-share-weighted sum of the log changes in each of the three components' price indexes from 2004-2014. Note that all three industries saw drops in their value added price indices over the period, which is why the figure in 2014 dollars is smaller than the 2004 figure. An alternative approach of deflating each industry's 2004 nominal value added by the industry-specific deflator and summing the result implies 2004 real value added in 2014 dollars of $\$ 836.2$ billion. The difference in the methods mostly reflects the effect of the $37 \%$ decline in the computer equipment manufacturing price index during the period. Note that using this latter figure for 2004 value added in the calculations below would make the "missing" output of the mismeasurement hypothesis even larger in terms of the industries' measured incremental value added.
} 
added would have had to have grown by $170 \%$ from 2004-2015, almost triple the measured growth.

Looking at the dual to this calculation — that is, through the lens of a price deflator-is also instructive. The Tornqvist value added price index for the industry bundle fell $13.2 \%$ over 2004-2014, a CAGR of -1.4\%. If real GDP growth has been misstated because deflators have improperly accounted for quality changes in these products, the true deflator would be that which raises measured real value added growth by the extra $\$ 2.7$ trillion. This deflator would have a CAGR of -9.3\% (sustained over 11 years) — seven times the magnitude of the actual deflator. Prices would have fallen not by 15\% since the slowdown began but 65\% instead.

Some of the industries' outputs are intermediate inputs used to make other products. Therefore they do not directly deliver surplus to final demanders. It is possible that some of the gains from the new technologies might arise as (again mismeasured) productivity gains in the production of goods for which they are used as inputs. ${ }^{14}$ If this were the case, the total “multiplier” effect of technological progress through input use is captured by the industry's ratio of gross output (revenues) to value added (Domar, 1961; Hulten, 1978). Incremental revenues capture the gains associated not just with the industry's products per se but also any embodied productivity gains obtained through their use as inputs. To gauge the potential influence of this usage, I repeat the calculations above using revenues (gross output) in place of value added.

The nominal gross output of the three sectors in 2014 was \$2.25 trillion (\$387.1 billion in computer/electronics manufacturing, \$1510.8 billion in information, and \$353.4 billion in computer systems design and services). The corresponding values in 2004 were \$1.67 trillion (\$391.6 billion, \$1080.2 billion, and \$195.4 billion). Again applying the BEA price deflators (this time for gross output) to express these values in 2014 dollars yields a real gross output of \$1.62 trillion. Average annual nominal gross output growth from 2011-2014 was 4.1\%; for real gross output growth it was 3.7\%. Extrapolating from 2014 to 2015 yields an estimated gross output of \$2.34 trillion in 2015, and a 2004 gross output in 2015 dollars of \$1.68 trillion.

Incremental real gross output (i.e., real revenue) for the industries was therefore about $\$ 660$ billion. A full accounting for the mismeasurement hypothesis would imply an increment to consumer surplus that is four times as large as this. Had such a surplus been captured in revenue

\footnotetext{
${ }^{14}$ In the 2013 input-output tables (the latest available), 75\% of computer equipment manufacturing output was used as an intermediate in the production of another commodity. The corresponding values for information and computer services were $44 \%$ and $43 \%$, respectively.
} 
figures, the industries' real revenues would have tripled over 2004-2015, rather than risen 40\% as observed in the data. The dual calculation implies a mismeasurement-corrected deflator with a CAGR of $-6.7 \%$ over 2004-2015 instead of the actual Tornqvist gross output price index CAGR of $-0.3 \%$, for a total price decline of $54 \%$ rather than $4 \%$.

These calculations reveal how severely one must believe the measured growth of these industries understates their true growth if measurement problems are to explain the productivity slowdown. What was measured and what would have actually had to happen would be multiples apart.

A final set of calculations reinforces this point. If the data miss industry output growth, they of course also miss productivity growth. In this case, that is a lot of missing productivity. These industries, combined, saw their total employment rise 3.6\% over 2004-2015 (from 5.58 million to 5.78 million, about $0.3 \%$ annually). Assuming they actually produced all of the output lost to the productivity slowdown, real value added per worker, properly measured, would have risen by 363\% over those 11 years. This is an astounding rate of productivity growth. For example, it is notably larger than the $83 \%$ productivity growth seen in durable goods manufacturing during the productivity acceleration of 1995 to 2004, when durables had the fastest labor productivity growth of any major sector and they were a primary driver of the acceleration (Oliner, Sichel, and Stiroh, 2007).

Perhaps these numbers are not that surprising when one considers that these digitaltechnology industries accounted for only 7.7\% of GDP in 2004. A full accounting of the productivity slowdown by the mismeasurement hypothesis requires this modest share of economic activity to account for lost incremental output that in 2015 is about 15\% of GDPtwice the 2004 size of the entire sector. One should be mindful that it is possible that unmeasured incremental gains are being made in industries outside these. However, balancing this out is the fact that, as discussed above, the digital-product-focused industries here are defined expansively. It is doubtful that every segment in this grouping has experienced rapid technological progress.

\section{National Income versus National Product}

In national income accounting, gross domestic income- the sum of employee compensation, net operating surplus, net taxes on production and imports, and consumption of fixed capital (i.e., depreciation)_equals GDP by an identity. These are never equal in practice, 
however, because different data are used to construct each-income information on the one hand and expenditure data on the other.

In recent years, the gap between GDI and GDP—-the so-called "statistical discrepancy"has widened, with GDI on average outpacing GDP. Table 2 shows GDI, GDP, and the gap between them in annual data for 1995-2014. ${ }^{15}$ Over 2005-14, a cumulative gap of $\$ 650$ billion (nominal) grew between GDI and GDP. This is an average gap of about $0.4 \%$ of GDP per year, though not every single year saw domestic income exceed domestic product. One could argue that this gap reflects workers being paid to make products (whose labor earnings are included in GDI) that are being given away for free or at highly discounted prices relative to their value (reducing measured expenditures on these products and therefore GDP in turn). This would be an incidental indicator of the forces surmised by the mismeasurement hypothesis.

A closer examination of the data, however, strongly suggests that the GDI-GDP gap is not a sign of mismeasurement hypothesis.

First, as is clear in the table, the gap started opening before the productivity slowdown. GDI was larger than GDP in each of the seven years running from 1998 to 2004, all of which were a time of fast productivity growth. The average annual gap was $0.6 \%$ of GDP, even larger than in the slowdown period.

Second, a closer look at the composition of national income reveals patterns inconsistent with the "workers paid for making free products" story. The four rightmost columns in Table 2 follow the evolution of the shares of GDI paid to each of the four major income categories that comprise it. Between 2004 and 2014, employee compensation’s share of GDI fell by 2.2 percentage points while gross operating surplus grew by 1.6 percentage points. Net taxes' share fell by 0.1 percentage point and depreciation rose by 0.7 percentage points. Thus the GDI gains over the period were tied to payments to capital that came at the expense of labor income. ${ }^{16}$ Nor

\footnotetext{
${ }^{15}$ The BEA defines the statistical discrepancy as GDP minus GDI, so a negative reported value implies that GDI is larger than GDP. As I am focusing on the extent to which GDI is greater than GDP, I am discussing the behavior of the negative of the statistical discrepancy.

16 These income share changes are a reflection of the trends that other researchers (e.g., Elsby, Hobijn, and Şahin 2013 and Karabarbounis and Neiman 2014) have been exploring in other contexts. An alternative decomposition of income yields the same implications as those described here. This alternative divides national income (gross domestic income adjusted for international transfers minus depreciation) into employee compensation, proprietor's income, capital income (the sum of rental income, corporate profits, and net interest), and a residual category that is the sum of net taxes on production and imports plus business transfer payments plus the surplus of government enterprises. As with the results above, labor's share fell as capital's share rose over 2004-14. Employee compensation's share of national income fell by 2.6 percentage points while capital income grew by 2.9 percentage
} 
is this link between GDI and capital income only manifested in long differences; the correlation in annual data from 1995 to 2014 between the GDI-GDP gap and labor's share is -0.43 , while it is 0.67 for net operating surplus.

Growth in domestic income measures relative to measured domestic product therefore seems to reflect increases in capital income rather than labor income. “Abnormally” high measured income relative to measured expenditures is positively related to growth in businesses' profitability and negatively related to payments to employees. This is inconsistent with—and indeed implies the opposite of - the "pay people to build free goods” story.

\section{Conclusion}

In this note I have evaluated the argument that the decade-long slowdown in labor productivity growth is at least in part illusory, and instead is the consequence of measurement issues. Under this line of reasoning, which I term the mismeasurement hypothesis, true productivity growth has not slowed (or slowed considerably less than measured) since 2004, but recent gains have not been reflected in productivity statistics, either because new goods' total surplus has shifted from (measured) revenues to (unmeasured) consumer surplus, or because price indices are overstated.

My evaluation offers four pieces of evidence that pose challenges for the mismeasurement hypothesis. First, the productivity slowdown has occurred in dozens of advanced economies, and its magnitude is not related to measures of those economies' intensities of digital technology consumption or production. Second, estimates from previous research of the consumer surplus of internet access-which presumably embodies a large portion of the surplus created by the new technologies claimed by proponents of the hypothesis - are far from the missing \$2.7 trillion (conservatively speaking) of GDP lost to the productivity slowdown. The largest estimate by some distance, measured using very generous definitions of the value of leisure time, is less than one-third this amount. Third, for measurement problems to fully account for the lost output resulting from the productivity slowdown, the true real revenue growth rate of industries that produce and service information and communication technologies would have to be four times its measured growth rate (true value added growth would be five times its

points. (Proprietors' income share fell by 0.2 percentage points and the share of taxes fell by 0.1 percentage point over the period.) 
measured level. Even if these industries were supposed to only account for a substantial sharethough not most—of the lost output (say the one-third implied by the largest estimate of surplus from the literature), it would still be the case that in absence of measurement problems, real output growth would have to be multiples of their observed growth in the data. These implications reflect the fact that the productivity slowdown caused measured GDP to fall by 15\% of its counterfactual level, yet digital technology industries - which presumably are the source of most measurement problems arising since 2004-were only 7.7\% of GDP in 2004. Fourth, while measured gross domestic income has been on average higher than gross domestic product since 2004 - perhaps indicating workers are being paid to produce products that are given away for free or highly discounted prices - this trend actually began before the productivity slowdown. Even more problematically for the hypothesis, the widening of this gap appears to reflect unusually high capital income rather than labor income.

In summary, multiple basic patterns in the data pose challenges for mismeasurement based explanations for the productivity slowdown that the U.S. has been experiencing since 2004. Two patterns - the size of the slowdown across countries is uncorrelated with the ICT intensities of those countries' economies, and the GDI-GDP gap began opening before the slowdown and in any case reflects capital income growth-are flatly inconsistent with the implications of the mismeasurement hypothesis. Two others - the modest size of the existing literature's estimates of surplus from internet-linked products and the large implied missing growth rates of digital technology industries that the mismeasurement hypothesis would entailshow the quantitative hurdles the hypothesis must clear to account for a substantial share of what is an enormous amount of measured output lost to the slowdown (around \$8400 per person per year).

These results are suggestive. They do not definitively rule out the possibility that productivity measurement problems may have developed over the past decade for specific products or product classes. However, the combined weight of the patterns presented here makes clear that the intuitive and plausible empirical case for the mismeasurement hypothesis faces a higher bar in the data, at least in terms of its ability to account for a substantial portion of the measured output lost to the productivity slowdown. It also suggests that, more likely than not, 
much if not most of the productivity slowdown is real. ${ }^{17}$ Whether that slowdown will end anytime soon is an open question.

\footnotetext{
${ }^{17}$ One very speculative mechanism that would tie a true productivity slowdown to people spending a large share of their time on zero-to-low-marginal-price technologies would be if workers substituted work effort for technology consumption (e.g., spending time at work on social networking sites) after 2004. This would heighten consumer surplus in a way largely unmeasured by standard statistics while at the same time reducing output per hour-that is, measured labor productivity. Of course, to explain a slowdown in labor productivity growth, this substitution would need to be occurring in ever greater magnitudes over time.
} 


\section{References}

Alloway, Tracy. 2015. “Goldman: How ‘Grand Theft Auto’ Explains One of the Biggest Mysteries of the U.S. Economy.” Bloomberg Business, May 26, 2015. http://www.bloomberg.com/news/articles/2015-05-26/goldman-how-grand-theft-autoexplains-one-of-the-biggest-mysteries-of-the-u-s-economy

Baily, Martin Neil, James Manyika, and Shalabh Gupta. 2013. “U.S. Productivity Growth: An Optimistic Perspective.” International Productivity Monitor, 25: 3-12.

Becker, Gary S. 1965. “A Theory of the Allocation of Time.” Economic Journal, 75(299): 493517.

Brynjolfsson, Erik and Andrew McAfee. 2011. Race Against the Machine: How the Digital Revolution Is Accelerating Innovation, Driving Productivity, and Irreversibly Transforming Employment and the Economy (Lexington, Mass.: Digital Frontier Press)

Brynjolfsson, Erik and Andrew McAfee. 2014. The Second Machine Age: Work, Progress, and Prosperity in a Time of Brilliant Technologies (New York: W.W. Norton \& Company) Brynjolfsson, Erik and JooHee Oh. 2012. “The Attention Economy: Measuring the Value of Free Digital Services on the Internet.” Proceedings of the International Conference on Information Systems, Orlando.

Byrne, David M., Stephen D. Oliner, and Daniel E. Sichel. 2013. "Is the Information Technology Revolution Over?” International Productivity Monitor, 25: 20-36.

Byrne, David M., Stephen D. Oliner, and Daniel E. Sichel. 2015. "How Fast Are Semiconductor Prices Falling?” NBER Working Paper No. 21074.

Cardarelli, Roberto and Lusine Lusinyan. 2015. “U.S. Total Factor Productivity Slowdown: Evidence from the U.S. States.” IMF Working Paper WP/15/116.

Cette, Gilbert, John Fernald, and Benoît Mojon. 2015. “The Pre-Global-Financial-Crisis Slowdown in Productivity.” Working Paper.

Connolly, Ellis and Linus Gustafsson. 2013. “Australian Productivity Growth: Trends and Determinants.” Australian Economic Review, 46(4): 473-482.

Cowen, Tyler. 2011. The Great Stagnation: How America Ate All the Low-Hanging Fruit of Modern History, Got Sick, and Will (Eventually) Feel Better. (New York: Dutton) 
Davis, Steven J. and John Haltiwanger. 2014. “Labor Market Fluidity and Economic Performance.” NBER Working Paper No. 20479.

Decker, Ryan, John Haltiwanger, Ron Jarmin, and Javier Miranda. 2014. “The Role of

Entrepreneurship in US Job Creation and Economic Dynamism.” Journal of Economic Perspectives, 28(3): 3-24.

Diewert, W. Erwin and Kevin J. Fox. 1999. "Can Measurement Error Explain the Productivity Paradox?” Canadian Journal of Economics, 32(2): 251-280.

Domar, Evsey D. 1961. “On the Measurement of Technological Change.” Economic Journal, 71(284): 709-729.

Dutz, Mark, Jonathan Orszag, and Robert Willig. 2009. “The Substantial Consumer Benefits of Broadband Connectivity for US Households.” Mimeo.

Elsby, Michael W. L., Bart Hobijn, and Ayşegül Şahin. 2013. “The Decline of the U.S. Labor Share.” Brookings Papers on Economic Activity, Fall 2013, 1-63.

Feldstein, Martin. “The U.S. Underestimates Growth.” Wall Street Journal, May 18, 2015. Fernald, John. 2014. "Productivity and Potential Output Before, During, and After the Great Recession.” NBER Working Paper No. 20248.

Goodridge, Peter, Jonathan Haskel, and Gavin Wallis. 2015. “Accounting for the UK

Productivity Puzzle: A Decomposition and Predictions.” Imperial College London Discussion Paper 2015/02.

Goolsbee, Austan and Peter J. Klenow. 2006. "Valuing Consumer Products by the Time Spent Using Them: An Application to the Internet.” American Economic Review Papers and Proceedings, 96(2): 108-13.

Gordon, Robert J. 2015. The Rise and Fall of American Growth: The U.S. Standard of Living since the Civil War. Princeton, NJ: Princeton University Press.

Greenstein, Shane. 2013. “Measuring Consumer Surplus Online.” Economist. March 11, 2013.

Greenstein, Shane and Ryan C. McDevitt. 2009. “The Broadband Bonus: Accounting for Broadband Internet's Impact on U.S. GDP.” NBER Working Paper No. 14758.

Hatzius, Jan and Kris Dawsey. 2015. “Doing the Sums on Productivity Paradox v2.0.” Goldman Sachs U.S. Economics Analyst, No. 15/30.

Hulten, Charles R. 1978. “Growth Accounting with Intermediate Inputs.” Review of Economic Studies, 45(3): 511-518. 
Karabarbounis, Loukas and Brent Neiman. 2014. “The Global Decline of the Labor Share.” Quarterly Journal of Economics, 129(1), 61-103.

Klenow, Peter J. 2003. “Measuring Consumption Growth: The Impact of New and Better Products.” Federal Reserve Bank of Minneapolis Quarterly Review, 27(2): 10-23.

Mas, Matilde and Robert Stehrer (eds.). 2012. Industrial Productivity in Europe: Growth and Crisis. Northhampton, MA: Edward Elgar.

Mokyr, Joel. 2014. “Secular Stagnation? Not in Your Life.” In Secular Stagnation: Facts, Causes and Cures, Coen Teulings and Richard Baldwin, eds. London: CEPR Press. Oliner, Stephen D., Daniel E. Sichel, and Kevin J. Stiroh. 2007. “Explaining a Productive Decade.” Brookings Papers on Economic Activity, 2007(1): 81-152.

Nevo, Aviv, John L. Turner, and Jonathan W. Williams. 2015. "Usage-Based Pricing and Demand for Residential Broadband.” Working paper, available at http://ssrn.com/abstract=2330426.

Pessoa, João Paulo and John Van Reenen. 2014. “The UK Productivity and Jobs Puzzle: Does the Answer Lie in Wage Flexibility?” Economic Journal, 124(576): 433-452.

Rosston, Gregory L., Scott J. Savage, and Donald M. Waldman. 2010. "Household Demand for Broadband Internet in 2010.” B.E. Journal of Economic Analysis \& Policy: Advances, 10(1).

Smith, Noah. 2015. “The Internet’s Hidden Wealth.” Bloomberg View, June 6, 2015. http://www.bloombergview.com/articles/2015-06-10/wealth-created-by-the-internet-maynot-appear-in-gdp.

Syverson, Chad. 2013. "Will History Repeat Itself? Comments on "Is the Information Technology Revolution Over?” International Productivity Monitor, 25: 37-40.

Tarullo, Daniel K. 2014. “Longer-Term Challenges for the American Economy.” Speech given to 23rd Annual Hyman P. Minsky Conference: Stabilizing Financial Systems for Growth and Full Employment, Washington, D.C., April 9, 2014.

U.S. Congress. 1996. “Toward a More Accurate Measure of the Cost of Living: Final Report to the Senate Finance Committee from the Advisory Commission to Study the Consumer Price Index.” $104^{\text {th }}$ Congress, 2nd sess., S.Prt. 104-072. http://www.ssa.gov/history/reports/boskinrpt.html 
Table 1: Average Quarterly Labor Productivity Growth by Period

\begin{tabular}{ccc} 
Period & Avg. quarterly LP growth (\%) & Annualized LP growth (\%) \\
\hline $1947-1973$ & 0.681 & 2.73 \\
$1974-1994$ & 0.386 & 1.55 \\
$1995-2004$ & 0.711 & 2.84 \\
$2005-2015(Q 3)$ & 0.330 & 1.32
\end{tabular}

Notes: These values are taken from the BLS nonfarm private industry labor productivity growth series. Annualized growth values are simply four times quarterly growth. 
Figure 1a. Labor Productivity Growth Change between 1995-2004 and 2005-2014 versus Share of Households with Broadband Access ( $\mathrm{N}=25$ OECD countries)

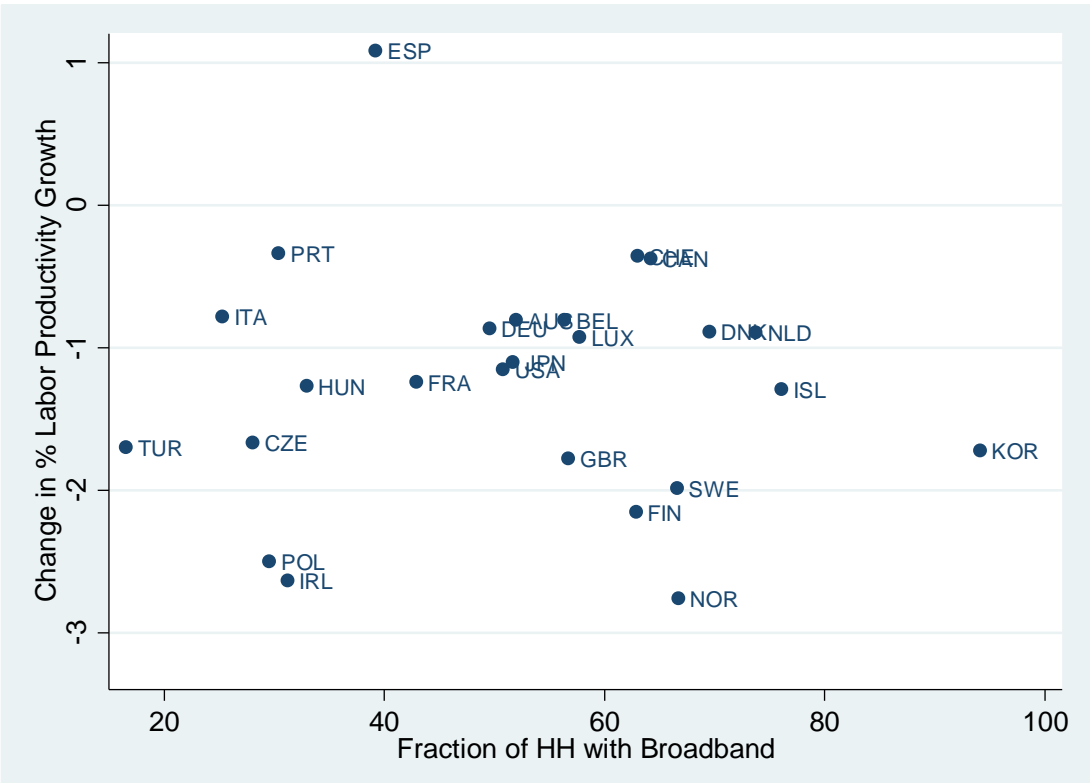

Figure 1b. Labor Productivity Growth Change between 1995-2004 and 2005-2014 versus ICT's Share of Value Added ( $\mathrm{N}=24$ OECD countries)

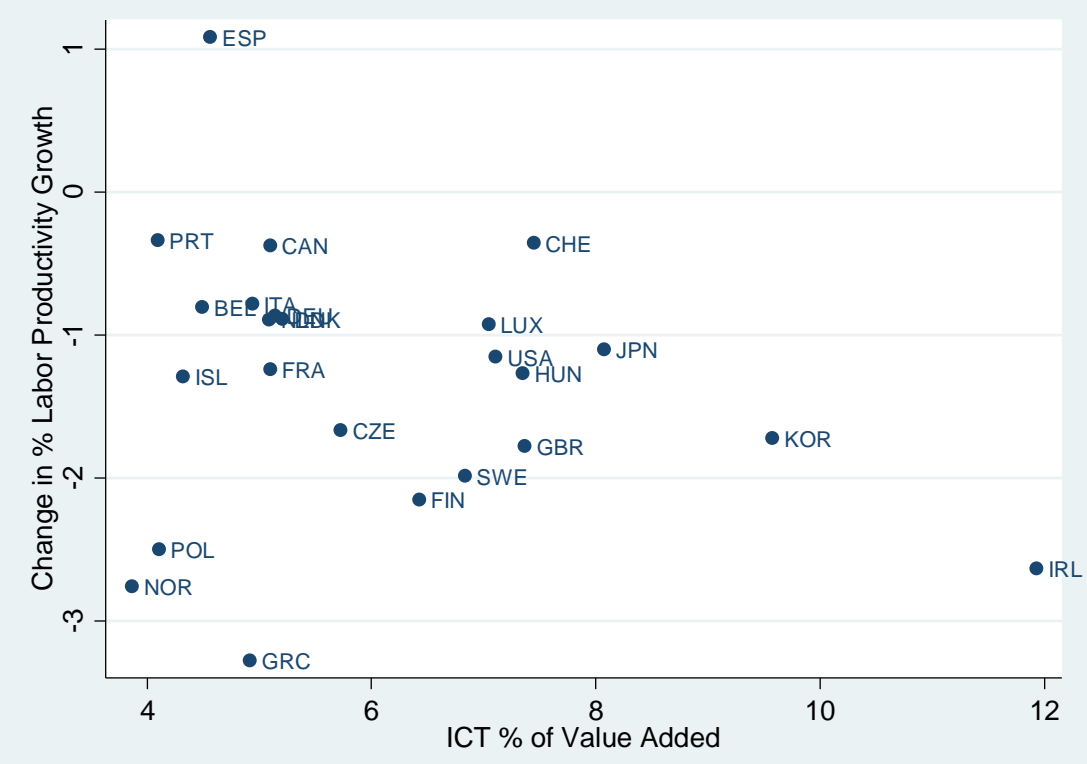

Notes: Data for both figures are from OECD. See text for details. 
Table 2. Gross Domestic Income vs. Gross Domestic Product

\begin{tabular}{cccccccc} 
& & \multicolumn{5}{c}{ Share of GDI going to } \\
Year & GDI & GDP & $\begin{array}{c}\text { GDI-GDP } \\
\text { gap }\end{array}$ & $\begin{array}{c}\text { Labor } \\
\text { income }\end{array}$ & $\begin{array}{c}\text { Net operating } \\
\text { surplus }\end{array}$ & Net taxes & Depreciation \\
1995 & 7573.5 & 7664.1 & -90.6 & 55.5 & 22.7 & 6.9 & 14.8 \\
1996 & 8043.6 & 8100.2 & -56.6 & 55.0 & 23.6 & 6.8 & 14.6 \\
1997 & 8596.2 & 8608.5 & -12.3 & 54.9 & 24.0 & 6.7 & 14.4 \\
1998 & 9149.3 & 9089.2 & 60.1 & 55.5 & 23.5 & 6.6 & 14.3 \\
1999 & 9698.1 & 9660.6 & 37.5 & 55.9 & 23.2 & 6.5 & 14.4 \\
2000 & $10,384.3$ & $10,284.8$ & 99.5 & 56.5 & 22.6 & 6.4 & 14.6 \\
2001 & $10,736.8$ & $10,621.8$ & 115 & 56.4 & 22.4 & 6.2 & 14.9 \\
2002 & $11,050.3$ & $10,977.5$ & 72.8 & 55.7 & 22.8 & 6.5 & 15.0 \\
2003 & $11,524.3$ & $11,510.7$ & 13.6 & 55.3 & 23.1 & 6.6 & 15.0 \\
2004 & $12,283.5$ & $12,274.9$ & 8.6 & 54.9 & 23.5 & 6.7 & 14.9 \\
2005 & $13,129.2$ & $13,093.7$ & 35.5 & 54.1 & 24.2 & 6.7 & 15.1 \\
2006 & $14,073.2$ & $13,855.9$ & 217.3 & 53.4 & 24.7 & 6.7 & 15.2 \\
2007 & $14,460.1$ & $14,477.6$ & -17.5 & 54.7 & 22.9 & 6.8 & 15.7 \\
2008 & $14,619.2$ & $14,718.6$ & -99.4 & 55.3 & 21.7 & 6.8 & 16.2 \\
2009 & $14,343.4$ & $14,418.7$ & -75.3 & 54.4 & 22.4 & 6.7 & 16.5 \\
2010 & $14,915.2$ & $14,964.4$ & -49.2 & 53.4 & 23.9 & 6.7 & 16.0 \\
2011 & $15,556.3$ & $15,517.9$ & 38.4 & 53.2 & 24.3 & 6.7 & 15.8 \\
2012 & $16,358.5$ & $16,155.3$ & 203.2 & 52.7 & 25.3 & 6.6 & 15.5 \\
2013 & $16,840.8$ & $16,663.2$ & 177.6 & 52.5 & 25.2 & 6.6 & 15.6 \\
2014 & $17,560.1$ & $17,348.1$ & 212 & 52.7 & 25.1 & 6.6 & 15.6
\end{tabular}

Notes: Data are from the BEA national income accounts Table 1.10. 